August 18, 2006

\title{
Executive Compensation and Investor Clientele
}

\author{
Laura L. Frieder* \\ Avanidhar Subrahmanyam**
}

*Krannert School of Management, Purdue University, 403 West State Street, West Lafayette, IN 47907; email: lilfrieds@purdue.edu; phone: (765) 494-4462.

**The Anderson School, University of California at Los Angeles, 110 Westwood Plaza, Los Angeles, CA 90095-1481; email: subra@anderson.ucla.edu; phone: (310) 825-2508.

We thank Raghu Rau and Charlene Sullivan for their many useful comments. 


\section{Abstract \\ Executive Compensation and Investor Clientele}

Executive compensation has increased dramatically in recent times, but so has trading volume and individual investor access to financial markets. We provide a model where some managers understate asset values through misleading statements in order to have enough of a cushion to compensate themselves. Owing to a lack of sophistication or naïveté, possibly arising from high opportunity costs of learning about accounting conventions and financial markets, small investors do not ascertain the extent of this behavior. Expected compensation is therefore higher when small investors form a more significant clientele in the market for a firm's stock. Increased precision of private information deters the entry of small investors and may keep executive compensation in check. Technologies that lower the cost of trading facilitate entry of small investors and raise expected compensation. Such compensation can in general be reduced through appropriate regulation and transparent disclosures. Empirical tests provide support to the key implication of the model that indirect executive compensation is higher in stocks with more retail investor participation. 


\section{Introduction}

Issues surrounding executive compensation have taken on increased prominence in recent times. A particular concern has been the climb in executive pay relative to national average salaries in recent years. For example, a report by the Internal Revenue Service indicates that between 1980 and 1995, total pay of CEOs rose by about $\$ 200$ billion, an increase of $182 \%$ on an inflation-adjusted basis. During this same period corporate profits rose by only $127 \%$, and wages of non-supervisory employees actually fell slightly. ${ }^{1}$ Furthermore, recent articles in the popular press observed that "CEO raises [from 2003 to 2004]...dwarfed that of the average worker", amounting to an aggregate $54 \%$ increase. $^{2}$ Mishel, Bernstein, and Allegretto (2005) note that the average CEO compensation soared $342 \%$ between 1989 and 2000 and that CEOs in 2003 were paid 185 times as much as the average worker while the corresponding ratio was only 26 in 1965 . Though surveys of the literature by Fama (1998) and Schwert (2003) conclude that the bulk of the empirical evidence supports semi-strong informational efficiency of financial markets, the ballooning of executive compensation has been difficult to explain using traditional frameworks that involve arguments based on "market discipline," i.e., those based on effective governance by boards of directors elected by astute shareholders.

Academics have focused considerable attention towards understanding compensation, particularly since the work of Jensen and Murphy (1990). Specifically, much research (e.g., Aggarwal and Samwick, 1990, Barro and Barro, 1990, and Kaplan, 1994) has focused on pay-for-performance sensitivities across different companies. The steep rise in relative levels of compensation over recent decades, however, warrants a separate investigation. A related issue is the lack of transparency about executive compensation packages. A recent article in the New York Times highlighted the case of Analog Devices,

\footnotetext{
${ }^{1}$ See, for example, an article by Louis Corrigan at http://www.fool.com/Rogue/1997/Rogue970905.htm.

${ }^{2}$ See "A Payday for Performance," by Louis Lavelle, Business Week online, April 18, 2005, and "CEO Compensation," by Scott DeCarlo, Forbes, April 21, 2005.
} 
which did not disclose deferred CEO compensation for a number of years. ${ }^{3}$ Also in the spotlight has been the apparent delinkage of compensation with financial performance. ${ }^{4}$ Spurred by these concerns, the SEC has recently mandated clearer disclosure of executive compensation.

These issues surrounding compensation of top management are not insignificant. For example, Bebchuk and Fried (2003) indicate that the pay of the top five best-paid U.S. executives amounts to as much as $10 \%$ of their company's profits. Bebchuk and Grinstein (2005) suggest that the dramatic growth of non-equity compensation in the 1990s has not been matched by a corresponding decrease in equity-based compensation. In a wellfunctioning capital market where market oriented governance mechanisms (i.e., boards representing shareholders) are supposed to limit excesses, how can the increasing trend in executive compensation both in absolute terms and in relation to the average employee be rationalized?

In this paper, we address the preceding question by linking the stylized facts on executive compensation to another seemingly disparate set of stylized facts, namely that trading volume has also increased dramatically over time, as has individual investor access to markets. Chordia, Huh, and Subrahmanyam (2005) report that turnover increased by $500 \%$ over the 1980 to 2002 period, and it is well-known that average bid-ask spreads have declined steeply in recent years (Jones, 2002). At the same time, technologies such as the advent of online trading, as well as secular regulatory events such as the lowering of the tick size, have increased access to the financial markets. ${ }^{5}$ It is possible that cheaper access to markets and the corresponding increase in trading activity are connected to the trend in executive compensation. One way in which this may occur is via the degree of sophistication of the investing clientele in a company. Specifically, suppose that lower

\footnotetext{
3 "A 'Holy Cow' Moment in Payland," by Gretchen Morgenson, New York Times, 2/19/2006.

${ }^{4}$ See, for example, "Cendant Chief's Compensation Soared in 2005," by Ryan Chittum, Wall Street Journal, March 2, 2006, or "At Visteon, Bonuses Defy Gravity," by Floyd Norris, New York Times April $14,2006$.

${ }^{5}$ Heaton and Lucas (1999) document the sharp increase in the number of shareholders in U.S. stocks during the 1990s.
} 
trading costs attract more individual investors. ${ }^{6}$ Indeed, such investors appear content to trade in financial markets where they lose money on average (Odean, 1998 and 1999 and Kumar, 2005), perhaps because cognitive limitations and outside activities create high opportunity costs of learning about financial markets as well as accounting rules and conventions. $^{7}$ It seems reasonable, then, to postulate that their lack of sophistication may be related to executive compensation. ${ }^{8}$

We build on the preceding idea by developing a simple model that links managerial compensation to the clientele that holds a firm's stock. The starting point of the framework is that some managers attempt to enrich themselves as much as possible at the expense of shareholders. ${ }^{9}$ Their desire to do so is limited only by the ability of outside shareholders to monitor their wages and total compensation (viz. Burkart, Gromb, and Panunzi, 1997, Hartzell and Starks, 2003, and Efendi, Srivastava, and Swanson, 2006). Based on Odean $(1998,1999)$ and Kumar (2005) who provide evidence that, on average, individuals trading stock lose money, it appears reasonable to postulate that these agents derive direct utility from trading. Therefore, key factors in the decision of an individual investor to participate in financial markets are his monetary-equivalent utility from trading, the illiquidity cost he expects to incur by losing money on average to more sophisticated traders, and the ex ante costs of entry. ${ }^{10}$ We further postulate that, unlike sophisticated institutional traders who are effective at governance, individual investors are unable to decipher and monitor executive compensation effectively. For example, naïve investors are unlikely to detect practices like spring-loading and backdat-

\footnotetext{
${ }^{6}$ Evidence from the NYSE website indicates the increased participation of individual investors in recent years. For example, the share of orders within the size range 100-2,099 shares in total NYSE volume was as low as $12.7 \%$ in January 1989 but climbed to as high as $50.8 \%$ by December 2005 .

${ }^{7}$ See also Benartzi and Thaler (2001), Lo, Repin, and Steenbarger (2005), or Hong, Stein, and Yu (2005) for evidence regarding investor naïveté about financial markets. More generally, for evidence that agents often have naïve notions about complex issues (such as scientific inquiry or the intricacies of scientific subjects such as physics), see Reif (1995).

${ }^{8}$ Only active shareholders who present a credible threat to replace the board of directors can ensure that the board is objective in determining compensation.

${ }^{9}$ Our work, unlike that of Bolton, Scheinkman, and Xiong (2006), does not focus on the choice between short-term and long-term investment projects and their relation to investor clientele.

${ }^{10}$ Such costs can be monetary (e.g., resources consumed in setting up a brokerage account) as well as cognitive (e.g., the costs of learning about the stock market).
} 
ing options (Lie, 2005) which essentially transfer wealth from shareholders to executives. Concealed arrangements, consisting of deferred compensation, post-retirement income guarantees, and stock option packages, are not only challenging to value but likely difficult to understand. ${ }^{11}$

The challenges faced by individual investors in properly deciphering compensation packages imply that, in equilibria where such agents find it worthwhile to trade, expected executive compensation is greater than otherwise. The model suggests that technological innovations that make it cheaper to trade stocks increase the tendency for individual investors to be more strongly represented in the shareholding clientele and managers will be more likely to successfully misrepresent their compensation to outsiders and concomitantly increase their true compensation. An increase in executive compensation may then simply be explained by a decrease in the sophistication of the clientele that trades a company's stock. ${ }^{12}$

\footnotetext{
${ }^{11}$ A press release dated July 6, 2006 from Reuters notes that more than 50 companies' option granting practices are being investigated. See also http://online.wsj.com/public/resources/documents/infooptionsscore06-full.html for an updated list of companies currently under examination for options scandals. Other recent articles have focused on how details of compensation packages are hard to decipher. See, for example, "Spotlight on Pay Could Be a Wild Card," by Stephen Labaton, New York Times, April 9, 2006, "Congress Seeks to Rein In Special Executive Pensions," by Michael Schroeder, Wall Street Journal, January 25, 2006, and "Man of Letters: Bogle Joins Campaign Urging SEC To Act on Executive Pay - And Cites His New Book," by Paul Davies, Wall Street Journal, April 15, 2006. An article titled "Is 'Total Pay' that Tough to Grasp?," by Gretchen Morgenson, New York Times, July 9, 2006, notes that a recent report on executive compensation by a forum of executives, the Business Roundtable, excluded significant amounts of hard-to-grasp aspects of executive compensation, including dividends, realized gains on stock options, as well as pension benefits, deferred compensation, and money received in severance packages, and that these aspects increased executive compensation well beyond the numbers provided in the report.

${ }^{12}$ Gabaix and Landier (2006) explain the rise in executive compensation by linking it to a rise in market capitalization. In their model, top executives of larger firms are paid more simply because they span a larger asset base. This model, however, explains neither why pay appears to be delinked from performance (Bebchuk and Grinstein, 2005, Bebchuk, Fried, and Walker, 2002), nor why there is an impetus to increase disclosure, presumably in response to efforts by management to hide true compensation (viz. Footnote 11). Some papers (e.g., Dow and Raposo, 2006) have attributed the rise in CEO pay to the greater incentives required due to increased uncertainty in recent times, but this argument has been challenged in a calibrated model by Gayle and Miller (2005). In a recent paper, Hermalin (2006) argues that tighter corporate governance increases CEO pay because there is less job security, but again, the issues surrounding concealment of compensation are not addressed by this argument. Furthermore, the evidence suggests that lack of adequate corporate governance, rather than too much of it, is the issue (Bebchuk and Fried, 2004). In sum, it appears that there is room in the literature for understanding corporate governance from different viewpoints.
} 
We also show that while an increase in the precision of private information possessed by sophisticated institutions decreases liquidity, it can keep executive compensation in check by deterring the entry of individual investors. Finally, we analyze how increased disclosure requirements such as the Sarbanes-Oxley Act (2002) can lead to an upward revision of mean executive compensation by non-investing agents and result in an impetus to lower executive compensation.

We test some empirical implications of our model using executive compensation data. We provide evidence that executive compensation is directly linked to trading volume and, more specifically, that indirect executive compensation is positively related to small trade volume and return variance, and negatively related to institutional holdings. These results are consistent with the notion that highly volatile stocks (to which individuals are likely to be attracted (Kumar, 2005)) as well as stocks with greater individual investor participation have greater levels of indirect compensation.

This paper is organized as follows. Section 2 presents a simple model of individuals and institutions dealing with management that attempts to misrepresent resources available for compensation. Section 3 endogenizes the entry decision of individual investors. Section 4 discusses how non-investing agents learn about executive compensation. Section 5 provides results to empirical tests, and Section 6 concludes. Proofs appear in the appendix.

\section{The Basic Model}

We consider a simple model of a firm with assets that are dedicated to executive compensation and some uncorrelated ongoing projects that generate a random cash flow $F \equiv \bar{F}+\delta$, where $\bar{F}$ is non-stochastic and positive, and $\delta$ is a normally distributed variable with zero mean. In this section, we assume there is no trading on claims on the firm's cash flow. The minimum payment required to keep the manager employed in order to generate $F$ is a number $L$. Thus, $L$ can be construed to represent the reservation level 
of managerial compensation in the sense that without a minimum compensation of $L$, the manager quits the firm and the firm ceases to exist as a going concern. ${ }^{13}$

There are two types of investors, "individuals" and "institutions." While we make this sharp distinction within the model, our aim is simply to distinguish between sophisticated investors who can decipher compensation packages from company disclosures and less sophisticated ones who cannot. Thus, the former class of agents is termed "institutions" but could also include financially trained and wealthy individuals. The latter class of investors includes relatively less "specialized" individual investors who find the deciphering of disclosures to be a challenging exercise. The lack of sophistication can arise due to limited cognitive ability, combined with a relative lack of knowledge about accounting procedures and a high opportunity cost of learning about such rules and conventions. ${ }^{14,15}$

We model in a stylized fashion the outcomes on executive compensation that can obtain when different types of clientele hold shares in the company's stock. For brevity, however, we desist from modeling in detail the specific process of governance, e.g., election of the board of directors by plurality or some other method. ${ }^{16}$

We denote the value of the assets used to pay compensation as $W$. We assume that there are two possible beliefs about $W: H$ or $L$, with $H>L$. While the institution knows the true value of $W$ to be $H$, an outside individual investor believes that $W=L{ }^{17}$ At a

\footnotetext{
${ }^{13}$ The level of compensation is assumed to include wages as well other parts of the package such as retirement plans and deferred compensation schemes.

${ }^{14}$ Our supposition, as of scholars in psychology such as Wechsler (1958) and Jensen (1998), is that cognitive abilities vary in the cross-section of individuals; such differences can arise, for example, due to unequal access to quality education. We emphasize, however, that in no way should this paper be viewed as subscribing to the notion that there are inter-group differences in cognitive abilities. The results in Section 3.2 explicitly address differential cognitive abilities of individual investors and managers.

${ }^{15}$ One might question why unsophisticated individuals do not simply hold mutual funds. Based on prior literature (Odean, 1998 and 1999, and Kumar, 2005), we assume that individual investors derive some utility from trading, and will therefore trade as long as the sum of their expected profits from trading and the monetary-equivalent utility from trading exceeds entry costs.

${ }^{16}$ See "Deal Spurs Embarrassment of Riches: Capital One's Acquisition Of North Fork Throws Focus On the Actions of Directors," Wall Street Journal, March 18, 2006, for details on the different voting procedures followed by corporations.

${ }^{17}$ Our aim is to model a situation where managers can surreptitiously pay themselves extra compen-
} 
cost of $C_{I}$, the individual may investigate to ascertain the true value of $W .{ }^{18}$ Following the investigation, he may or may not be able to decipher the true realization of $W$. If he does investigate, he concludes $W=L$ with probability $p$ and $W=H$ with probability $1-p$. We initially suppose that there is a representative individual investor who, if present, holds a fraction $\beta$ of the firm's shares; the remainder are held by the institutional investor.

Governance is controlled by the board of directors (BOD). Each category of agents has a proportional share in the composition of the board. Suppose the institution is the only shareholder. In this case, we assume a fraction $\gamma$ of the BOD passively accepts the strategy proposed by the manager. However, this fraction is less than $50 \%$. Thus, if the institution is the only entity who holds shares in the firm, it is able to enforce the action that best serves its own interest.

We seek to capture the phenomena resulting from the possibility of individuals having a majority say in the governance of the firm, rather than institutions. Consequently, now consider the case when the individual holds a fraction $\beta$ of the shares. Then, the fraction of the institutional share of the BOD that is active becomes $(1-\gamma)(1-\beta)$. We assume that this quantity is less than 0.5. Thus, the institution is not able to control managerial strategies when the representative individual investor is present. We suppose that amongst the fraction of the BOD apportioned to the individual investor, a fraction $\alpha$ is passive. Further, we assume that the active portion of the BOD that the individual controls plus the total passive portion, $\gamma(1-\beta)+\beta$, is greater than $50 \%$, as

sation above their reservation wage if individual investors mistakenly believe that resources available for compensation are lower than the true level of such funds. This is captured by the notion that individual investor beliefs are anchored at $W=L$ while institutions know that $W=H$. The case where institutions correctly believe that $W$ equals $L$ is trivial because in this case there are no funds available to pay an extra compensation above the reservation wage. The case where both individuals and institutions correctly believe that $W=H$ does not allow for extra compensation over the reservation wage, because both groups of agents are able to extract the surplus $H-L$. Finally, in the case where individuals erroneously believe that $W=H$, whereas institutions correctly believe that $W=L$, there cannot be an extraction of surplus by outside investors (nor, trivially, the possibility of any extra compensation beyond $L$ ), because $L$ is the manager's reservation wage.

${ }^{18}$ Outside investors do not have perfect foresight expectations, in the spirit of the models of Barberis, Shleifer, and Vishny (1998), Daniel, Hirshleifer, and Subrahmanyam (1998), and Hong and Stein (1998). 
is the total active portion of the BOD, $(1-\beta)(1-\gamma)+\beta(1-\alpha)$. These assumptions are intended to ensure that when the individual investor is present, the compensation outcome is the result of whether the individual investor finds it worthwhile to undertake costly investigation in order to ascertain the true value of $W$.

The strategy space for the manager is as follows. The compensation proposed by the manager for approval by the BOD is always $L$ (the reservation wage), and this proposal, being the lowest possible compensation, is always accepted by the BOD. The manager also suggests not paying a dividend to shareholders with any left-over funds after paying out the compensation. Recall that the institution knows the value of $W$. Thus, if the institution is the only shareholder, it is able to pay itself an immediate dividend of $H-L$ through the majority of the BOD.

When the individual investor is present, the governance question is whether the surplus $H-L$ is paid as a dividend to the investors or secretly extorted by the manager as extra compensation. If the individual investor is present, decides to investigate, and assesses the true value to be $L$, then a majority of the BOD accepts that there are no funds available to pay an immediate dividend. This is because the total active portion of BOD controlled by the individual investor and the total passive portion (which simply accepts the manager's proposal of a zero dividend) is greater than $50 \%$. In this case, the manager pays himself an extra compensation of $H-L$ over $L$, i.e., a total compensation of $H$.

If, however, the individual investor assesses the value to be $H$, then the compensation is still $L$, but the investors capture the surplus through the BOD by way of an extra dividend of $H-L$ because the total active portion of the BOD is greater than $50 \%$ and both individuals and institutions are able to reject the manager's proposal of a zero dividend. Furthermore, if the individual investor is present and decides not to investigate, then the manager is again able to pay himself a total compensation of $H$ because, in this case, the individual investor is anchored at his prior belief that $W=L$. 
We also assume that if $W$ is concluded to be $H$ by the individual investor, he gets an immediate dividend of $\beta(H-L)$, with the institution getting the remainder. We consider cases where the individual investor is either present or absent and treat this agent's entry decision as exogenous in this section. ${ }^{19}$ In the next section, we endogenize the individual's entry decision.

The probability $p$ is a control value for the manager. The cost of misrepresentation is as follows. We suppose that an external regulatory agency can investigate managerial misrepresentation after time 0 but prior to the release of the firm's true value at time 1. While the costs and benefits of the agency are not incorporated into the analysis, we suppose that if the manager is found to have misrepresented (i.e., set a positive $p$ ), the penalty incurred is a positive quantity $C_{r}$. The penalty captures the reputational and monetary costs incurred by the manager after being discovered to have misrepresented or falsified the disclosure. ${ }^{20}$ The probability of being discovered as having misrepresented is $r{ }^{21}$ The expected reduction in the manager's payoff is thus $r C_{r}$. In addition, we assume that the probability $r$ is increasing in $p$. The notion is that an overly disingenuous assessment is more likely to be discovered by the regulatory agency than a somewhat less extreme one.

For tractability, we assume that the relationship between $r$ and $p$ can be represented as $r=0.5 k p^{2}$, where $k$ is a variable such that $0<k<1$. Thus, the cost of setting $p$ is $0.5 c p^{2}$, where $c=k r C_{r}{ }^{22}$ The cost of setting too high a $p$ then is that the misrepresentation is more likely to be discovered.

Assuming the individual investor is present and that he investigates, the manager

\footnotetext{
${ }^{19}$ The representative individual investor can be viewed as a coalition of outside investors. In Section 3.5 , we consider the case of multiple outside investors.

${ }^{20}$ The modeling of misrepresentation is closely related to the approach of Subrahmanyam (2005).

${ }^{21}$ The notion that misrepresentation is not verifiable with complete certainty is in the spirit of costly state verification models of Townsend (1979), Gale and Hellwig (1984), Larker and Weinberg (1989), Winton (1995), and Crocker and Morgan (1998).

${ }^{22}$ The parameter $c$ may also be construed as representing psychic costs (which captures the inherent disinclination to be dishonest), as in Becker (1976). Furthermore, the cost of misrepresentation may be inversely related to managerial cognitive ability: "smarter" managers may be able to misrepresent more effectively, as pointed out by Subrahmanyam (2005).
} 
maximizes his net expected extra payoff,

$$
p(H-L)-0.5 c p^{2}
$$

which yields

$$
p=\frac{H-L}{c} .
$$

Since $H>L$ and $c>0, p$ is strictly positive. For $p<1$, we need $H-L<c$, and we will assume that this condition holds. Furthermore, we will often treat $p$ as a given parameter in the model, while implicitly recognizing its dependence on other parameters through (1). The expected compensation, assuming investigation, is $L$ plus the expected extra compensation arising from misrepresentation. Denoting the mean compensation by $E(W)$, we then have

$$
E(W)=\frac{(H-L)^{2}}{2 k r C_{r}}+L .
$$

Now let us consider the individual investor's problem. Note that this agent will investigate if

$$
\beta(1-p)(H-L)>C_{I} .
$$

Thus, in equilibrium, there will be misrepresentation and investigation so long as

$$
\beta\left[1-c^{-1}(H-L)\right](H-L)>C_{I} .
$$

This leads us to the following proposition, which follows directly from the above discussion.

Proposition 1 1. Ex ante expected executive compensation is lower when the individual investor is not present as a stockholder.

2. If the individual investor is present as a stockholder, expected executive compensation is higher when the individual investor does not investigate than when he does. 
The above proposition proves our basic result that if relatively naïve individual investors are present in the market, managers are able to randomize on the variable that represents their true compensation and hence raise the ex ante expected compensation. In the next section, we model the individual investor's entry into the financial market.

\section{The Securities Market}

We now model the individual investor's decision to trade in the market for the firm's securities. As pointed out earlier, the claims traded are not on executive compensation but on a separate project, which pays $F=\bar{F}+\delta$. This separation helps maintain tractability but is of no other material consequence for the purposes of our intuition. In general, executive compensation amounts are not overwhelming relative to the firm's overall cash flows, so this assumed delinkage to keep the model straightforward is not unreasonable.

\subsection{Endogenous Entry with a Single Individual Investor}

We will assume a standard adverse selection model of market microstructure for trading claims on the project with a payoff of $F$. Private information is possessed by the single institutional investor who observes $\delta$ perfectly. If the individual investor is present, the noise demand is contributed by this agent and totals $z$ where $z \sim N\left(0, v_{z}\right)$. As usual, the price $P$ set by a risk-neutral market marker is a linear function of the total order flow $Q$, and takes the form $P=\bar{F}+\zeta Q .{ }^{23}$ If the individual investor does not participate in the market, then, in effect, there is no market because there is no liquidity or noise trading. Assuming the individual investor participates, this implies that (in the spirit of Admati and Pfleiderer, 1988, Kyle 1985, or Subrahmanyam, 1991) the illiquidity parameter $\zeta$ in this market is given by

$$
\zeta=\frac{1}{2} \sqrt{v_{\delta} v_{z}^{-1}}
$$

\footnotetext{
${ }^{23}$ For convenience, we assume that unlimited short-sales are allowed.
} 
Note that the individual investor earns negative expected profits in our setting since he has no private information. This is consistent with the work of Kumar (2005) and Odean $(1998,1999)$ who indicate that individual investors seem to actively trade stocks even if they earn inferior returns. We thus assume that the individual investor directly derives utility from trading (as a consumption good) and that the monetary equivalent of this is $K$. In addition, we suppose a fixed cost $C_{E}$ has to paid by the individual to enter the stock market. This can be interpreted as the setup costs associated with opening a brokerage account and cognitive costs involved in familiarizing oneself with the equity markets and the trading process.

It is well-known that in our setting (see, e.g., Admati and Pfleiderer, 1988), the expected losses of the uninformed individual investor to the informed agents are $\zeta v_{z}{ }^{24}$ Also note that once the agent enters the market he has an option (but not the obligation) to investigate.

The above observations imply that the agent will enter into the market for the firm's stock if

$$
K-C_{E}+\max \left[\beta(1-p)(H-L)-C_{I}, 0\right]>\zeta v_{z}
$$

i.e., if

$$
K-C_{E}+\max \left[\beta(1-p)(H-L)-C_{I}, 0\right]>0.5 \operatorname{std}(\delta) \operatorname{std}(z)
$$

where $\operatorname{std}(x)$ denotes the standard deviation of a random variable $x$, and $p$ is given by (1). The conditions that encourage entry are a low $C_{E}$, a high $K$, and a smaller standard deviation of information.

This leads us to the following proposition.

Proposition 2 1. The individual investor enters the market whenever the cost of entry and the variance of the cash flows $\left(v_{\delta}\right)$, is sufficiently low, and the monetary equivalent of utility from trading is sufficiently high.

\footnotetext{
${ }^{24}$ To see this, note that the losses are given by the negative of $E[(F-P) z]$. Substituting $P=\bar{F}+\zeta Q$ yields the expression in question.
} 
2. Expected executive compensation, trading volume, and liquidity are higher when the individual investor enters the stock market than when he does not.

3. Given that the individual investor enters the stock market, expected executive compensation is greater when the agent does not investigate than when he does.

Within our setting, if the individual investor enters, he de facto obtains control of the firm's governance. This presents the problem that due to naïveté, the agent may not be able to decipher compensation packages accurately, which, in turn, precludes the agent from forcing the compensation down to $L$, and therefore leads to increased executive compensation on average. Note that policies that reduce the cost of financial market access, i.e., the parameter $C_{E}$, increase the parameter set under which the individual investor enters. Therefore expected executive compensation is greater when the cost of entry is lower. This argument suggests that easing access to financial markets by way of technologies such as online trading do create liquidity but have the possibly unintended consequence of introducing individual investors whose lack of sophistication or cognitive limitations allow managers to misrepresent and thereby increase expected compensation.

\subsection{Cognition and Executive Compensation}

To illustrate the dependence of executive compensation on managerial and investorspecific attributes, we provide some simple extensions of the analysis in the previous section. Substituting for $p$ from (1) and assuming that

$$
\beta\left(1-\frac{H-L}{c}\right)(H-L)-C_{I}>0
$$

the condition in (4) becomes

$$
K-\left(C_{E}+C_{I}\right)+\beta\left(1-\frac{H-L}{c}\right)(H-L)-0.5 \operatorname{std}(\delta) \operatorname{std}(z)>0 .
$$

Recall that $c$ is the expected managerial cost from being caught as having misrepresented $W$. It is reasonable to suppose that $c$ is decreasing in managerial cognitive ability (more 
specifically, we can assume that $r$, the probability of being caught, is inversely related to this attribute, as pointed out in Footnote 22). At the same time it can be assumed that $C_{I}$, the cost of investigation, is inversely related to the individual investor's cognitive ability. These observations lead to the following proposition.

Proposition 3 The tendency for the individual investor to enter is greater when managerial cognitive ability is lower and when the cognitive ability of the individual investor is higher.

Note that the effect of increasing managerial cognitive ability, say $i$, on expected executive compensation is subtle. We have assumed that $C_{I}^{\prime}(i)<0$. Thus, start from a point where $i$ is big enough that the individual investor does not enter. If we decrease it to a point where the investor does enter, executive compensation jumps from $L$ to a higher number. But if we decrease $i$ further, this decreases $p$, and from (1) and (2), this actually reduces expected managerial compensation. The reduction however, is never all the way back to $L$, the compensation when the individual investor does not enter at all. So, on net, starting from $i$ low enough that condition (5) does not hold, and ending at a point where it does hold, expected executive compensation increases.

As a further extension, consider the case of the parameter $K$. This parameter may also be a function of individual investors' cognitive ability, say $i_{o}$. Specifically, Kumar (2005) states that the propensity to invest in lotteries is greater for poor and relatively less-educated agents and suggests that the same type of agents may also gamble in the stock market. These agents are likely to be relatively less sophisticated, possibly because of limited access to good education. As such, based on the notion that cognitive ability is a function of education quality, $K$, the utility from trading, may be negatively related to cognitive ability, i.e., $K^{\prime}\left(i_{o}\right)<0$. This creates some tension. Increasing $i_{o}$ decreases $C_{I}$, the cost of investigation, but it also decreases $K$. The net effect on the tendency of the individual investor to enter depends on the relative sizes of $K^{\prime}\left(i_{o}\right)$ and $C_{I}^{\prime}\left(i_{o}\right)$. Specifically, the condition under which increasing $i_{o}$ increases the tendency of the 
individual to enter is $\left|C_{I}^{\prime}\left(i_{o}\right)\right|>\left|K^{\prime}\left(i_{o}\right)\right|$. Thus, if investigation costs go down sufficiently strongly at the margin relative to the decrease in trading utility $K$, then an increase in $i_{o}$ will increase the tendency of the individual investor to enter and raise expected executive compensation.

Finally, we consider an alternative parameterization where $c$ is not just a function of $i$, but a function of the differential $i-i_{o}$. The notion is that the differential between managerial cognitive ability and that of individuals influences the likelihood of the misrepresentation succeeding. ${ }^{25}$ In this situation, keeping $i$ fixed, the effect of increasing $i_{o}$ on the left-hand side of (4) is a bit complex and is described by the following proposition.

Proposition 4 Suppose that the expected cost of managerial misrepresentation, $c$, depends on $i-i_{o}$, the difference between managerial and individual investors' cognitive ability. Then, keeping $i$ fixed, increasing $i_{o}$ increases the left-hand side of the entry condition (4) and thus increases the tendency for the individual investor to enter the financial market if and only if the condition

$$
\frac{\beta(H-L)^{2} c^{\prime}\left(i-i_{o}\right)}{c^{2}}-C_{I}^{\prime}\left(i_{o}\right)>\left|K^{\prime}\left(i_{o}\right)\right|
$$

holds.

Thus, so long as the expected increase in the dividend (represented by $H-L$ ), the share of the corporation held by the individual $\beta$, and the sensitivity of the expected cost of misrepresentation to individual cognitive ability are sufficiently large, increasing $i_{o}$ increases the tendency of the individual to enter.

\footnotetext{
${ }^{25}$ We assume that this differential is always positive in that managers have higher cognitive ability than individual investors, because a high cognitive ability is required to run public corporations effectively. See Subrahmanyam (2005) for a detailed justification of this assumption.
} 


\subsection{The Effect of Signal Precision}

\subsubsection{The Quality of Private Information and Individual Investors}

For the remainder of the paper, we go back to the setting in Subsection 3.1 and remove the dependence of parameters on cognitive ability, because the main thrust of the points we wish to make does not rely on the analysis in Subsection 3.2. We now consider an interesting extension of our basic setting when the institution observes $\delta$ with some noise. We suppose that the information signal is $\delta+\epsilon$ where $\epsilon \sim N\left(0, v_{\epsilon}\right)$ and is independent of all other random variables. The illiquidity parameter $\zeta$ becomes (see the appendix)

$$
\zeta=\frac{v_{\delta}}{2} \sqrt{\frac{1}{\left(v_{\delta}+v_{\epsilon}\right) v_{z}}} .
$$

The above expression is decreasing in $v_{\epsilon}$. The equivalent of (4) now becomes

$$
K-C_{E}+\max \left[\beta(1-p)(H-L)-C_{I}, 0\right]>\frac{v_{\delta}}{2} \sqrt{\frac{v_{z}}{v_{\delta}+v_{\epsilon}}} .
$$

This leads us to the following proposition.

Proposition 5 An increase in the precision of private information reduces the parameter set under which the individual investor participates in the financial market and therefore tends to reduce expected executive compensation.

Basically, since the right-hand side becomes smaller as $v_{\epsilon}$ (which is inversely related to signal precision) becomes larger, increasing the precision of information makes it less likely that the individual investor will enter. Thus, an increase in the precision of the private signal, that traditionally is supposed to hurt financial markets by increasing adverse selection, actually increases the likelihood that more sophisticated agents will be holding a firm's stock. This enables more effective control of executive compensation. A benefit of more accurate private information (either as inside information or by way of advance access to an analyst's signal - viz. Green, 2006) thus is that it allows for more successful managerial monitoring by deterring the entry of unsophisticated traders. 


\subsubsection{The Effect of Policies Which Reduce Signal Precision}

Suppose regulatory authorities can preclude the trading on certain types of precise signals (e.g., by way of prohibiting trading on material information). Would it necessarily be optimal to enforce such regulations? Of course, a full analysis of this question requires consideration of fairness in the form of equal access to information. Abstracting from considerations of this type, consider the following tradeoffs in the context of our model. Increasing signal precision tends to deter the entry of individual investors. This allows for improved governance and thereby facilitates extra payments to shareholders while precluding extra executive compensation. Yet, it also reduces the liquidity of the financial market. Thus, the net effect is ambiguous.

To formalize the above notion consider that the regulatory authority seeks to maximize the objective $w\left(\zeta^{-1}\right)+(1-w) E(D)$, where $\zeta$ is the illiquidity parameter and $E(D)$ is the expected extra dividend paid to all investors out of $W$. In the base model considered thus far, $\zeta^{-1}$ is zero when the individual investor is not present (as $\zeta \rightarrow \infty$ when the individual is not present). Consider two levels of signal noise variances, $v_{\epsilon}^{G}$ and $v_{\epsilon}^{S}$, where $v_{\epsilon}^{G}>v_{\epsilon}^{S}$. Suppose policymakers can choose one of the two signal precisions by way of appropriate regulations on the types of information that can be traded upon. ${ }^{26}$ Further, suppose that

$$
\frac{v_{\delta}}{2} \sqrt{\frac{v_{z}}{v_{\delta}+v_{\epsilon}^{G}}}<K-C_{E}+\max \left[\beta(1-p)(H-L)-C_{I}, 0\right]<\frac{v_{\delta}}{2} \sqrt{\frac{v_{z}}{v_{\delta}+v_{\epsilon}^{S}}} .
$$

This implies that the individual enters the financial market only when the signal noise variance is $v_{\epsilon}^{G}$. In this scenario, one can state the following proposition.

Proposition 6 If $v_{\epsilon}^{G}$ is high enough and $v_{\epsilon}^{S}$ is low enough such that (9) holds, and if

$$
p(1-w)(H-L)>2 w v_{\delta}^{-1} \sqrt{\left(v_{\delta}+v_{\epsilon}^{S}\right) v_{z}},
$$

then the optimal choice of the regulatory authority is the lower signal noise or higher signal precision represented by $v_{\epsilon}^{S}$.

\footnotetext{
${ }^{26}$ The assumption here is that it is prohibitively costly to trade on both types of information, so only one signal is available and it can have one of two levels of signal precision.
} 
Thus, in cases where the weight placed on minimizing executive excess is large enough and the weight on liquidity is low enough, the optimal response of the regulatory authority may indeed be to allow trading on a signal with higher precision.

\subsection{Implications}

To develop cross-sectional implications using the above analysis, we rely on the model as well as out-of-model arguments. We conjecture that managers of complex firms are more likely to misrepresent compensation than those of focused firms, because individual investors are less able to decipher the complicated accounting statements of such firms with many lines of business. In turn, this implies that cases of obfuscated disclosures and misrepresented compensation are more likely to arise in large firms than in small, focused

firms. In formal terms, the parameter $c$ (related to the probability of detection) is likely to be small for diversified firms. Thus, true compensation is likely to be more difficult to decipher for larger, more complex, corporations. Closer investigation following increased transparency should reveal greater levels of hidden compensation for such companies (e.g., in the form of hard-to-detect deferments and retirement packages).

Another set of implications relates to how we expect the entry cost $C_{E}$ and the utility from trading $K$ to vary across individual investors. One may presume that $C_{E}$ is inversely related to the sophistication of the individual investor. One proxy for sophistication is the wealth of the agent. While direct proxies for wealth may not be available, indirect evidence may be obtained by stock liquidity. Thus, more liquid stocks consist of more small noise traders with high entry costs. Our analysis predicts greater average compensation in more liquid stocks. Similarly, lottery-type stocks with high skewness and volatility (as defined by Kumar, 2005) may provide greater pleasure from trade (i.e., $K$ may be greater in such stocks), leading to more unsophisticated clientele and hence greater expected compensation in such stocks. 


\subsection{Many individual investors}

We now extend our analysis to many individual investors. For convenience, we use the model where the information about $\delta$ is perfect. Suppose that there are $I$ individual investors present in the stock market. The assumptions about the BOD share controlled by individuals as a group and the fraction of the BOD that is passive remains unchanged from the previous section. We assume the noise demand is contributed to equally by each of the agents and thus totals $I z$, where $z \sim N\left(0, v_{z}\right)$. This implies that the illiquidity parameter $\zeta$ is given by

$$
\zeta=\frac{1}{2 I} \sqrt{\frac{v_{\delta}}{v_{z}}}
$$

when each of the $I$ individuals participates in the stock market. The total number of individual investors is bounded above by $I_{m}$. For convenience, we assume $I$ is a continuous variable (it can be interpreted as the total mass of individual investors in the market).

Again, each individual investor derives utility from trading (as a consumption good), and the monetary equivalent of this is $K$. As before, the cost of participation is $C_{E}$. Each investor can investigate and the probability of any one investor concluding that $W=L$ is $p$. For simplicity, we assume that it requires the conclusion of $W=H$ by a single investor in order for that investor to form a coalition and thereby communicate with other investors, and subsequently force the payment of an extra dividend $H-$ $L{ }^{27}$ Further, this facility is independent of the number of individual investors that trade in the financial market. If the compensation is indeed $L$, the dividend received by each individual investor is $\beta I^{-1}(H-L)$. Note that the probability of any one investor uncovering the misrepresentation is $1-p^{I}$, i.e., one minus the probability of nobody discovering the same.

We assume that if the $I^{\prime}$ th investor enters, all other agents who are not individual investors change their strategies in a consistent fashion in response to this move (as in

\footnotetext{
${ }^{27}$ More complicated communication rules are possible, for example, one could require a critical mass of investors to conclude that $W=L$ before the compensation is forced to $L$. Modeling such rules, however, would detract from the central points we wish to make.
} 
Admati and Pfleiderer, 1988). Under these conditions, assuming $I-1$ investors are already present, an I'th investor will enter if

$$
K-C_{E}+\max \left[\beta I^{-1}\left(1-p^{I}\right)(H-L)-C_{I}, 0\right]>(2 I)^{-1} \operatorname{std}(\delta) \operatorname{std}(z) .
$$

It can be seen from the above condition that if $K-C_{E}>0$, then, so long as $I_{m}$ is sufficiently high, there will always exist an equilibrium where all $I_{m}$ individual investors enter the market. In addition to this, however, if each agent is infinitesimally small there also may exist an equilibrium where none of the agents investigates because $\zeta$ is unboundedly large with just one agent in the market so that none of the agents wishes to enter given that the others do not enter. There also is a knife-edge equilibrium where $I_{e}$ agents enter, where $I_{e}$ is that number for which the condition in (11) holds as an equality. Another issue in the equilibrium where all $I_{m}$ agents enter is whether they investigate in order to attempt to ascertain $W$. Note, however, that if $C_{I}$ is low enough relative to $I_{m}$, they will all investigate. We will assume that $C_{I}$ is sufficiently small that this is indeed the case. Thus, the equilibrium value of $p$ (from a simple modification of $(1)$ ) is the $I$ th root of $(H-L) / c$.

One can relax various assumptions and analyze the different equilibria of this setting, but our basic focus is on the notion that limited cognitive abilities of individual investors prevent the deciphering of the true executive compensation package and thereby raise expected executive compensation. So we again have the following proposition:

Proposition 7 1. Assuming that $K>C_{E}$, the equilibrium under which all individual investors enter exists so long as the maximum number of such investors is sufficiently large.

2. Expected executive compensation is higher when all individual investors enter the stock market than when nobody does.

3. Given that all individual investors do enter the stock market, expected executive compensation is greater when they do not investigate than when they do. 
In general, when the population of individual investors is large, it will be more likely that they all enter because of two reasons. First, their presence makes the market more liquid, which benefits them all. Second, they are more likely to discover the obfuscated compensation if there are more of them. The countervailing force is that when there are more individual investors, they receive less of the share of the surplus $H-L$ generated when managerial misrepresentation is discovered. The basic result, that individual investors increase expected compensation, survives in this scenario as well. An implication of the analysis is that stocks which attract more individual investors (perhaps due to their lottery-like characteristics as per Kumar, 2005) are likely to have greater misrepresentations of compensation and excessive compensation packages than others.

\section{Learning by Non-Investing Agents about Compen- sation Packages}

In recent times, the large compensation packages of prominent executives have come under sharp focus by the popular press. Indeed, a slew of recent articles have critiqued what have been perceived to be excessive compensation packages. ${ }^{28}$ Until now, however, while we have considered individuals, institutions, and managers, we have not considered how non-investing agents like the popular press update their beliefs about compensation packages.

To analyze the above issue, we now model a setting where non-investing agents dynamically form expectations about compensation packages for multiple firms. We assume that there are $M$ homogeneous firms and consider the model with a single individual investor for each firm. ${ }^{29}$ The variable representing compensation assets is denoted $W_{j}$ for firm $j$, and is independent across firms. From the perspective of the non-investing agent,

\footnotetext{
${ }^{28}$ Two examples of articles in the popular press are "CEO pay soars in 2005 as a select group break the $\$ 100$ million mark," by Gary Strauss and Barbara Hansen, USA Today, April 10, 2006, and "For Consultants, It Can Pay to Back the Boss's Big Raise," by Gretchen Morgenson, New York Times, April 10, 2006.

${ }^{29}$ Extension to many individual investors per firm is straightforward and simply involves analyzing the equilibrium where all individuals enter the market for the firm.
} 
the ex ante probability of $W_{j}=H$ for any given firm is $q$. Further, the signal about the compensation value (i.e., what the individual investor concludes about compensation) is the same for the non-investing agent as that for the individual investor, and is denoted by $s_{j}$. Note that the compensation will be $L$ whenever the $\left(W_{j}, s_{j}\right)$ pairs are $(H, H)(L, L)$ and will be $H$ whenever $W_{j}=H$ but $s_{j}=L$. The event that $s_{j}=H$ when $W_{j}=L$ is not possible, because the manager of a firm with $W_{j}=L$ cannot gain by randomization.

Each firm's market operates independently from that of other firms and the managers and investors are homogeneous agents unique to each firm, and there are no cross-firm information flows. There is a single non-investing agent per firm. Assuming beliefs consistent with Bayes' rule, we have

$$
\operatorname{Pr}\left(W_{j}=H \mid s_{j}=L\right)=\frac{p q}{p q+1-q}
$$

and

$$
\operatorname{Pr}\left(W_{j}=L \mid s_{j}=L\right)=\frac{1-q}{p q+1-q} .
$$

The above expressions capture the dependence of the updating rule on the randomization probability $p$. When $s=L$, the probability of the event that $W_{j}=H$ increases in $p$ and the reverse is true for the probability that $W_{j}=L$.

Henceforth, we will assume for simplicity that $H=1$ and $L=0$. Let there be $M^{\prime}$ firms whose non-investing agent concludes $s_{j}=0$. We consider only these firms because for the case $s_{j}=1$, the compensation is always zero. Let the prior probability $\gamma \equiv \operatorname{Pr}\left(W_{j}=1 \mid s=0\right.$ ) (from the perspective of non-investing agents) be given by $\gamma_{p}$, and assume that $\gamma_{p}$ has a beta distribution with parameters $\gamma_{1}$ and $\gamma_{2}$. The variable $\gamma_{p}$ thus represents the parameter of a Bernoulli distribution from which true values of $W_{j}$ 's for the $M^{\prime}$ firms are drawn, and is identical across firms, given the homogeneity assumption. The mean of the prior distribution of $\gamma_{p}$ is different from $p q /[p q+1-q]$, the true point estimate of $\gamma$. This means that non-investing agents mis-estimate the extent of misrepresentation by managers. ${ }^{30}$ Note that the compensation is 1 when the assessment

\footnotetext{
${ }^{30}$ Again, the assumption of expectations at odds with Bayesian updating based on true parameters
} 
is $s_{j}=0$ for a firm whose true $W_{j}$ is 1 . This implies that the expected compensation is

$$
[q p+1-q] \gamma_{p}
$$

Assume that there is a second round in which, after ex post revelations of the values of $W_{j}$, a new generation of managers, BOD, and non-investing agents are randomly reassigned to the $M$ firms, and firm values conditional on $s_{j}=0$ are re-drawn from the same distribution as earlier, with a new replay of the full model. Suppose $n$ firms reveal $W_{j}=1$ and, of those, $m$ firms have $s_{j}=0$. Further, a new generation of noninvesting updates the prior on $\gamma_{p}$ using information on firm value revelations. Under these conditions, the following proposition obtains:

Proposition 8 The expected executive compensation assessed by non-investing agents in the second round (after agents learn and update their estimate of $\gamma_{p}$ ) is greater than that in the first round if and only if

$$
\frac{m}{n}>\frac{\gamma_{1}}{2 \gamma_{1}+\gamma_{2}}
$$

Since the above condition will be satisfied for $m / n$ large, after a large proportion of erroneous signal generations (i.e., $s_{j}=0$ for firms where $W_{j}=1$ ), we predict an upward revision in expected compensation levels. ${ }^{31}$ We would expect the revelation event to occur after increased, more stringent disclosure requirements. Events such as the SarbanesOxley act may well act as catalysts for belief revisions of the type in Proposition 8. The recent clamor for reducing excessive compensation packages in the popular press then can be linked directly to the revision in beliefs regarding executive compensation. ${ }^{32}$

is in the spirit of recent behavioral models such as Barberis, Shleifer, and Vishny (1998). If $\gamma_{p}$ is lower than the true value of $\gamma$, then this is consistent with a bias towards trust (since it is consistent with $p$ being underestimated). A trust bias is documented in the psychological literature (e.g., Uslaner, 1988). Further, Berg, Dickhaut, and McCabe (1995), and Forsythe, Lundholm, and Rietz (1999) provide experimental evidence in favor of the notion that agents are prone to trust.

${ }^{31}$ We note here that even after exposures of misrepresentation and after a large sample of $W_{j}$ revelations, self-attribution bias (e.g., Bem, 1965, Langer and Roth, 1975), wherein outcomes inconsistent with agents' expectations are attributed to extraneous causes rather than bias, may impede investors' dynamic learning about the true probability of misrepresentation, $p$.

${ }^{32}$ See the articles mentioned in Footnote 28. 


\section{Empirical Tests}

Our basic argument is that there would be more cases of obfuscated compensation in firms that are more liquid, and more complex. Since not all cases of misrepresented compensation are detected, the theory is inherently difficult to test. However, our theoretical results suggest that the characteristics of the firm may play a role in executive compensation, and the goal of this section is provide empirical tests of some of the model's implications. Specifically, our analysis predicts that executive compensation is positively related to liquidity, volatility, and proxies for firm complexity. The theory also implies that forms of indirect compensation would be strongly related to the extent of small investor trading.

In the empirical analysis that follows, we focus on fiscal year 2001, the most recent year for which we could obtain data. ${ }^{33}$ We also restrict ourselves to NYSE/AMEX stocks for two reasons. First, as we will see, our variables require transactions data, which are voluminous, and this restriction keeps our exercise manageable. Second, we wish to exclude very small Nasdaq stocks with possibly error-prone compensation and trade data in our analysis. Because our phenomena are likely to be less strong in stocks listed on NYSE/AMEX, owing to the fact listing on these exchanges is subject to more stringent disclosure requirements, this restriction works against the likelihood of finding support for our theses.

Compensation and shareholding data are from the executive compensation (Execucomp) database on Wharton Research Data Services (WRDS). These data are collected from each company's annual proxy, which must be filed 120 days after each company's fiscal year end. Execucomp collects data for up to 9 executives per firm for a given year, though the majority of companies report data for only 5. As the dependent variable in

\footnotetext{
${ }^{33}$ We found the results to be essentially unchanged upon performing Fama-Macbeth regressions for the period 1993 (the first year of reliable Execucomp data) to 2001 and using Newey and West (1987) corrections for the $t$-statistics to account for serial correlation in the residuals. Since detailed compensation data are not available prior to 1993, we have only eight years worth of data; hence, we do not report these results in the main text.
} 
our regressions, we use the average of each firm's mean total current compensation across executives. Total compensation (reported in thousands of dollars) is comprised of salary, bonus, and all other compensation including option grants. We choose to have firm-level averages rather than executive-level data because our regressors are at the firm level. For robustness, we use two versions of the dependent variable; the first averages data for the top five executives (ranked by total current compensation), while the second averages across all executives whose compensation levels are reported by Execucomp.

The controls are as follows. We include total annual dollar volume (in billions of dollars) as a measure of liquidity. As proxies for a variable that is likely to attract individual investor interest, we use the standard deviation and skewness of daily returns over the year (Kumar, 2005). We capture firm complexity by the number of business segments (obtained from Compustat) and firm size, measured by market capitalization (obtained from CRSP, in thousands of dollars) as of the end of the year. We also include the compounded stock return over the past thirty-six months as a link to an incentive mechanism whereby managers receive greater compensation when their stock performs well. ${ }^{34}$

In order to account for skewness in the characteristics, we use logarithms of all variables except of those that are return-related. This implies that in our regressions, we only use those observations with non-zero values of the variables before the logarithmic transformation. The total sample consists of 842 firms. Table 1 presents summary statistics associated with our variables. We retain in our sample those firms that report data for at least five executives, yet over $80 \%$ of firms in our sample report for only five executives. Thus, total compensation is averaged across the top five executives for each firm, ranked by total compensation. Many variables show considerable skewness (the

\footnotetext{
${ }^{34} \mathrm{We}$ used alternative proxies for the link to an incentive mechanism, such as sales and net income growth over the past two years, but found that these did not perform materially better than the return variable. We also used CEO tenure as an explanatory control for compensation, but found that this variable was not significant. Finally, we used the book value of assets in place of market capitalization, but found that the latter variable was more important in the regressions. These results are available upon request.
} 
mean is frequently quite different from the median), justifying the use of logarithmic transformations.

Table 2 reports the results from the cross-sectional regression of total executive compensation on the independent variables. ${ }^{35}$ In the middle panel, we average total compensation over the top five executives (ranked by total compensation), and average over all executives in the rightmost panel.

Within both regressions, we find that trading volume is strongly and positively related to compensation along with return volatility and size, and the adjusted $R^{2}$, just under 59\%, appears healthy. These results lend support to the notion that executive compensation is higher for more liquid firms, which also are more complex (as measured by firm size). ${ }^{36}$

Our analysis further suggests specific predictions about indirect compensation by implying that such compensation, being more difficult to decipher than total compensation, will be greater not only in stocks that have greater individual investor participation but also in those that attract greater interest from individuals. Thus, we employ the logarithm of indirect compensation relative to total compensation as the dependent variable. Our measure of indirect compensation is the sum of long-term incentive payouts (payments emanating from incentives set by management) and all other compensation (excluding salary and bonus). Such other compensation can include severance payments, debt forgiveness, payment for unused vacation, tax reimbursements, signing bonuses, $401 \mathrm{~K}$ contributions, life insurance premiums, and so on.

Results from using the indirect compensation measure as our dependent variable are presented in Table 3. None of the explanatory variables are significant at the $5 \%$ level,

\footnotetext{
${ }^{35}$ White-corrections for heteroskedasticity left the estimates virtually unchanged, so we report the uncorrected OLS estimates. Additionally, results are qualitatively unchanged if we use only direct compensation as the dependent variable.

${ }^{36}$ We also tried to ascertain whether total and indirect compensation levels are significantly different in the computer/high-tech sector as defined by Fama and French (1997) (SIC codes 3570-3579, 3680-3689, 3695 , and 7373). The rationale is that high tech companies with a high emphasis on human capital for success may require stronger incentives for management. However, inclusion of a high tech indicator variable made no material difference to the results as the dummy coefficient was insignificant.
} 
though the variable corresponding to the number of geographic segments is of the right sign and is significant at the $10 \%$ level. It is possible, however, that total volume may not be the best way to capture the activities of relatively unsophisticated investors. Thus, for a more in-depth exploration, we next account for individual investor interest by including relative volume from small orders. Following Barclay and Warner (1993), who classify orders less than 500 shares as "small", we measure small trade volume as the dollar volume emanating from orders of 500 shares or less. The variable we use is small order volume scaled by total volume. As an additional check, we include (a logistic transformation of) the proportion of a company's stock held by institutions (obtained from Standard \& Poor's) as an explanatory variable.

We find that the coefficient of small order volume is significantly positive. Further, the holdings variable comes in negative and significant. Consistent with our theoretical predictions, results from these regressions imply that stocks with smaller institutional holdings (and imputed greater individual holdings) have greater levels indirect compensation relative to total compensation. Results for all reported execucomp executives per firm appear in the last two columns of Table 3. The results are similar to those for the top five executives (ranked by indirect compensation), except that the number of geographic segments is positive and significant at the $5 \%$ level for this case, providing some evidence that more complex firms have greater indirect compensation.

From the perspective of economic significance, a $10 \%$ rise in relative small order volume implies about a $4 \%$ increase in indirect compensation, based on the relevant coefficient in the third column of Table 3, which seems material. Overall, the empirical results lend reasonable support to the ideas developed in our paper.

\section{Conclusion}

In this paper, we attempt to understand steep rises in executive compensation in firms which trade on large, liquid, financial markets. Specifically, we analyze how investor 
clientele interacts with managerial compensation. In our framework, some managers have an incentive to underrepresent the value of the firm's assets in order to provide themselves with free cash flow for excess compensation. The optimal disclosure policy trades off this incentive against regulatory penalties if managers are detected as having indulged in such activity.

Within the above setting, our basic argument is that individual investors with limited sophistication have difficulty in ascertaining true executive compensation from financial disclosures. An optimal level of misrepresentation in compensation is obtained by consideration of the degree of investor sophistication together with regulatory penalties. We show that the greater is retail investor participation, the greater is expected executive compensation. Our empirical analysis suggests that total as well as indirect compensation are positively related to trading volume. Indirect compensation is negatively related to institutional holdings. These results are consistent with the postulated theoretical notion that stocks with greater liquidity and greater individual investor participation are associated with greater levels of direct and indirect compensation.

Our analysis suggests that policies which improve access to capital markets can increase expected executive compensation because governance may pass to investors who are unable to decipher true compensation from disclosures. Greater precision of private information reduces liquidity but has a potential benefit in that it can discourage individual investors from participating in financial markets and thereby maintain a check on executive compensation. Increased penalties for fraudulent disclosures and increasing disclosure transparency can also lower expected executive compensation. 


\section{References}

Admati, A., and P. Pfleiderer, 1988, A theory of intraday patterns: Volume and price variability, Review of Financial Studies 1, 3-40.

Aggarwal, R., and A. Samwick, 1999, "The other side of the tradeoff: The impact of risk on executive compensation," Journal of Political Economy 107, 65-105.

Barberis, N., A. Shleifer, and R. Vishny, 1998, A model of investor sentiment, Journal of Financial Economics 49, 307-343.

Barclay, M., and J. Warner, 1993, Stealth trading and volatility: Which trades move prices?, Journal of Financial Economics 34, 281-306.

Bar-Gill, O., and L. Bebchuk, 2003, Misreporting corporate performance, working paper, Harvard Law School.

Barro, J., and R. Barro, 1990, Pay, performance, and turnover of bank CEOs, Journal of Labor Economics 8, 448-481.

Bebchuk, L., and J. Fried. 2003, Executive compensation as an agency problem, Journal of Economic Perspectives 17, 7192.

Bebchuk, L., and J. Fried, 2004, Pay without Performance: The Unfulfilled Promise of Executive Compensation, Harvard University Press, Cambridge, MA.

Bebchuk, L., J. Fried, and D. Walker, 2002, Managerial power and rent extraction in the design of executive compensation, University of Chicago Law Review 69, 751-846.

Bebchuk, L. and Y. Grinstein, 2005, The growth of U.S. executive pay, working paper, Cornell University.

Becker, 1968, Crime and punishment: An economic approach, Journal of Political Economy $76,169-217$.

Becker, G., 1976, The Economic Approach to Human Behavior, University of Chicago Press, Chicago, IL. 
Bem, D., 1965, An experimental analysis of self-persuasion, Journal of Experimental Social Psychology 1, 199-218.

Benartzi, S., and R. Thaler, 2001, Naïve diversification strategies in retirement saving plans, American Economic Review 91, 79-98.

Berg, J., J. Dickhaut, and K. McCabe, 1995, Trust, reciprocity, and social history, Games and Economic Behavior 10, 122-142.

Bolton, P., J. Scheinkman, and W. Xiong, 2006, Executive compensation and short-termist behavior in speculative markets, working paper, Princeton University.

Burkart, M., D. Gromb, and F. Panunzi, 1997, Large shareholders, monitoring, and the value of the firm, Quarterly Journal of Economics 112, 693-728.

Chidambaran, N., and K. John, 2001, Managerial compensation, voluntary disclosure, and large shareholder monitoring, working paper, New York University.

Chordia, T., S. Huh, and A. Subrahmanyam, 2005, The cross-section of expected trading activity, forthcoming, Review of Financial Studies.

Daniel, K., D. Hirshleifer, and A. Subrahmanyam, 1998, Investor psychology and security market under- and overreactions, Journal of Finance 53, 1839-1885.

DeGroot, M., 1989, Probability and Statistics (2nd edition), Addison-Wesley Publishing Company, Reading, MA.

Diamond, D., 1985, Optimal release of information by firms, Journal of Finance 40, 10711094.

Dow, J., and C. Raposo, 2006, CEO compensation, change, and corporate strategy, forthcoming, Journal of Finance.

Durnev, A., and E. Kim, 2005, To steal or not to steal: Firm attributes, legal environment, and valuation, Journal of Finance 60, 1461-1493.

Efendi, J., A. Srivastava, and E. Swanson, 2006, Why do corporate managers misstate financial statements? The role of in-the-money options and other incentives, working 
paper, Texas A\&M University.

Fama, E., 1998, Market efficiency, long-term returns, and behavioral finance, Journal of Financial Economics 49, 283-306.

Fama, E., and K. French, 1997, Industry costs of equity, Journal of Financial Economics 43, 153-193.

Forsythe, R., R. Lundholm, and T. Rietz, 1999, Cheap talk, fraud, and adverse selection in financial markets: Some experimental evidence, Review of Financial Studies 12, 481-518.

Gabaix, X., and A. Landier, 2006, Why has CEO pay increased so much?, working paper, University of Chicago.

Gayle, G., and R. Miller, 2005, Has moral hazard become a more important factor in managerial compensation?, working paper, Carnegie Mellon University.

Green, C., 2006, The value of client access to analyst recommendations, Journal of Financial and Quantitative Analysis 41, 1-24.

Hall, B., and K. Murphy, 2002, Stock options for undiversified executives, Journal of Accounting and Economics 33, 3-42.

Hartzell, J., and L. Starks, 2003, Institutional investors and executive compensation, Journal of Finance 58, 2351-2374.

Heaton, J., and D. Lucas, 1999, Stock prices and fundamentals, working paper, University of Chicago.

Hermalin, B., 2006, Trends in corporate governance, forthcoming, Journal of Finance.

Hirshleifer, D., S. Lim, and S. Teoh, 2002, Limited attention, information disclosure, and financial reporting, Journal of Accounting and Economics 36, 337-386.

Holmström, B., 1999, Managerial incentive problems: A dynamic perspective, NBER Working Paper \#6875.

Hong, H., J. Stein, and J. Yu, 2005, Simple forecasts and paradigm shifts, forthcoming, 
Journal of Finance.

Jenkins, H., 2002, Business world: Outrageous CEO pay revisited, Wall Street Journal, Oct 2, 2002, p. A17.

Jensen, A., 1998, The g Factor: The Science of Mental Ability, Praeger Publishers, Westport, CT.

Jensen, M., and W. Meckling, 1976, Theory of the firm: Managerial behavior, agency costs and ownership structure, Journal of Financial Economics 3, 305-360.

Jensen, M., and K. Murphy, 1990, Performance pay and top-management incentives, Journal of Political Economy 98, 225-264.

John, K., and T. John, 1993, Top-management compensation and capital structure, Journal of Finance 48, 949-974.

Johnson, S., R. Harvey, and Y. Tian, 2003, Executive compensation and corporate fraud, working paper, Texas A\&M University.

Jones, C., 2002, A century of stock market liquidity and trading costs, working paper, Columbia University.

Jones, K., and J. Day, 1997, Discrimination of two aspects of cognitive-social intelligence from academic intelligence, Journal of Educational Psychology 89, 486-497.

Kaplan, S., 1994, Top executive rewards and firm performance: A comparison of Japan and the United States, Journal of Political Economy 102, 510-546.

Kumar, A., 2005, Who gambles in the stock market?, working paper, University of Texas at Austin.

Lacker, J., and J. Weinberg, 1989, Optimal contracts under costly state falsification, Journal of Political Economy 97, 1345-1363.

Langer, E., and J. Roth, 1975, Heads I win tails it's chance: The illusion of control as a function of the sequence of outcomes in a purely chance task, Journal of Personality and Social Psychology 32, 951-955. 
Lavelle, L., 2002, How to halt the options express, Business Week, September 9, 2002, p. 26.

Lie, E., 2005, On the timing of CEO stock option awards, Management Science 51, 802-812.

Lo, A., D. Repin, and B. Steenbarger, 2005, Fear and greed in financial markets: A clinical study of day traders, working paper, Massachusetts Institute of Technology.

Malmendier, U., and G. Tate, 2003, CEO overconfidence and corporate investment, working paper, Stanford University.

Mishel, L., J. Bernstein, and S. Allegretto, 2005, The state of working America 2004/2005, working paper, Cornell University.

Morton, S., 1993, Strategic auditing for fraud, Accounting Review 68, 825-839.

Murphy, K., 2003, Stock-based pay in new economy firms, Journal of Accounting and Economics 34, 129-147.

Narayanan, M., 1985, Managerial incentives for short-term results, Journal of Finance 40, 1469-1484.

Narayanan, M., 1996, Forms of compensation and managerial decision horizon, Journal of Financial and Quantitative Analysis 31, 467-491.

Newey, W., and K. West, 1987, A simple positive semi-definite, heteroskedasticity and autocorrelation consistent covariance matrix, Econometrica 55, 703-708.

Odean, T., 1998, Are investors reluctant to realize their losses?, Journal of Finance 53, $1775-1795$

Odean, T., 1999, Do investors trade too much?, American Economic Review 89, 1279-1298.

Povel, P., R. Singh, and A. Winton, 2003, Booms, busts, and fraud, working paper, University of Minnesota.

Prendergast, C., 1999, Provision of incentives in firms, Journal of Economic Literature 37, 7-64. 
Reif, F., 1995, Understanding and teaching important scientific thought processes, Journal of Science Education and Technology 4, 261-282.

Ronen, J., and V. Yaari, 2002, Incentives for voluntary disclosure, Journal of Financial Markets 5, 349-390.

Ross, S., 1977, The determination of financial structure: The incentive-signalling approach, Bell Journal of Economics 8, 23-40.

Rotter, J., 1967, A new scale for the measurement of interpersonal trust, Journal of Personality 35, 651-665.

Schweizer, K., A. Beck-Seyffer, and R. Schneider, 1999, Cognitive bias of optimism and its influence on psychological well-being, Psychological Reports 84, 627-636.

Schwert, G., 2003, Anomalies and market efficiency, chapter 17 of the Handbook of Economics and Finance (G. Constantinides, M. Harris, and R. Stulz, eds.), North Holland, Amsterdam, Netherlands.

Shibano, T., 1990, Assessing audit risk from errors and irregularities, Journal of Accounting Research 28, 110-140.

Stulz, R., and R. Williamson, 2003, Culture, openness, and finance, Journal of Financial Economics 70, 313-349.

Subrahmanyam, A., 1991, A theory of trading in stock index futures, Review of Financial Studies 4, 17-51.

Subrahmanyam, A., 2005, A cognitive theory of corporate disclosures, Financial Management 34, 5-33.

Subrahmanyam, A., and S. Titman, 1999, The going-public decision and the development of financial markets, Journal of Finance 54, 1045-1082.

Subrahmanyam, A., and S. Titman, 2001, Feedback from stock prices to cash flows, Journal of Finance 56, 2389-2413.

Thaler, R., 1999, The end of behavioral finance, Financial Analysts Journal 55 (Novem- 
ber/December), 12-17.

Townsend, R., 1979, Optimal contracts and competitive markets with costly state verification, Journal of Economic Theory 21, 265-293.

Uslaner, E., 1998, Social capital, television, and the "mean world": Trust, optimism, and civic participation, Political Psychology 19, 441-467.

Wagman, M., 1996, Human intellect and cognitive science: Toward a general unified theory of intelligence, Praeger Publishers/Greenwood Publishing Group, Inc., Westport, CT.

Wechsler, D., 1958, The Measurement and Appraisal of Adult Intelligence, Williams and Wilkins, Baltimore, MD.

Winton, A., 1995, Costly state verification and multiple investors: The role of seniority, Review of Financial Studies 8, 91-123. 


\section{Appendix}

Proof of Proposition 1: If there is no investigation, the expected compensation is simply $H$. Furthermore, the right-hand side of (2) is less than $H$ because the first term on the right-hand side, which equals $0.5 p(H-L)$, is less than $H-L$.

Proof of Proposition 2: We first prove (3). The informed and noise traders submit market orders to the market maker who then quotes a price contingent on the net (combined) order flow of both types of traders. The informed maximizes his trading profit, given by

$$
E[\{(F-P) x\} \mid \delta] .
$$

Given a linear pricing rule $P=\bar{F}+\zeta Q$, where $Q=x+z$, his order works out to be $\delta / 2 \zeta$. The market maker sets prices such that $E(Q(P-v) \mid Q)=0$, so that $P=E(v \mid Q)$. From this, we have

$$
\zeta=\operatorname{cov}(\delta, Q) / \operatorname{var}(Q)
$$

We thus have

$$
\zeta=\frac{1}{2} \sqrt{\frac{v_{\delta}}{v_{z}}} .
$$

The proof of part 1 of Proposition 2 follows from a simple examination of the righthand side of the condition in (4). When only the institution is the shareholder, there is no camouflage for the informed agent, so trading volume and liquidity are zero. Thus, if the individual does enter the market, then compensation drops below $H$ and volume trivially rises from zero to a positive number. Further, liquidity (the inverse of $\zeta$ ) trivially increases from zero to the expression in (3). This proves Part 2. For part 3, it suffices to note that under investigation the compensation is greater than $L$ but smaller than $H$.

Proof of Proposition 3: Condition (4) that governs the entry of the individual investor, is given by

$$
K-\left(C_{E}+C_{I}\right)+\beta\left(1-\frac{H-L}{c}\right)(H-L)-0.5 \operatorname{std}(\delta) \operatorname{std}(z)>0 .
$$


If $c$ is decreasing in managerial cognitive ability, $i$, and if $C_{I}$ is decreasing in individual cognitive ability, $i_{o}$, then it is evident that decreasing $i$ and increasing $i_{o}$ will increase the left-hand side of (12) and thus increase the tendency for the individual to enter. $\square$.

Proof of Proposition 4: Differentiating the left-hand side of (4) with respect to $i_{o}$ (keeping $i$ fixed) yields

$$
K^{\prime}-C_{I}^{\prime}+\beta(H-L)\left[c^{-2}(H-L) c^{\prime}\right]
$$

where the dependence on $K, C_{I}$, and $c$ on $i_{o}$ and/or $i$ is suppressed for convenience. Note that when $i_{o}$ increases $C_{I}$ decreases, $K$ decreases, and $c$ increases. Thus, condition (13) reduces to

$$
\frac{\beta(H-L)^{2} c^{\prime}\left(i-i_{o}\right)}{c^{2}}-C_{I}^{\prime}\left(i_{o}\right)>\left|K^{\prime}\left(i_{o}\right)\right|,
$$

which is the condition in the proposition.

Proof of Equation (7): The informed maximizes expected profits given by $E[\{(F-$ $P) x\} \mid \delta+\epsilon]$, where $x$ is his chosen trade. Substituting for $F$ and $P=\bar{F}+\zeta Q$, where $Q$, as in the proof of (3), is the order flow, it follows that his order equals

$$
x=\frac{k(\delta+\epsilon)}{2 \zeta}
$$

where

$$
k \equiv \frac{v_{\delta}}{v_{\delta}+v_{\epsilon}}
$$

Let $\beta=\equiv /(2 \zeta)$. Then $\zeta$ is given by

$$
\zeta=\frac{\operatorname{cov}[\delta, \beta(\delta+\epsilon)+z]}{\operatorname{var}[\beta(\delta+\epsilon)+z]}
$$

implying

$$
\zeta=\frac{v_{\delta}}{2\left(v_{\delta}+v_{\epsilon}\right)} \sqrt{\frac{v_{\delta}+v_{\epsilon}}{v_{z}}}
$$

Proof of Proposition 5: The condition under which the individual investor enters is given by

$$
C_{E}-K+0.5 v_{\delta} \sqrt{\frac{v_{z}}{v_{\delta}+v_{\epsilon}}}<\max \left[\beta(1-p)(H-L)-C_{I}, 0\right]
$$


The left-hand side of this expression is decreasing in $v_{\epsilon}$, or increasing in signal precision. Thus, increasing precision decreases the parameter set under which the condition holds. Again, starting from a point where $v_{\epsilon}$ is low enough where the individual investor is present and increasing it high enough so that the individual investor exits, expected executive compensation rises.

Proof of Proposition 6: If

$$
K-C_{E}+\max \left[\beta(1-p)(H-L)-C_{I}, 0\right]<\frac{v_{\delta}}{2} \sqrt{\frac{v_{z}}{v_{\delta}+v_{\epsilon}^{S}}},
$$

then the individual investor does not enter when the signal noise variance is $v_{\epsilon}^{S}$. If

$$
K-C_{E}+\max \left[\beta(1-p)(H-L)-C_{I}, 0\right]>\frac{v_{\delta}}{2} \sqrt{\frac{v_{z}}{v_{\delta}+v_{\epsilon}^{G}}} .
$$

the individual enters the financial market when the signal noise variance is $v_{\epsilon}^{G}$. Now, if the individual investor does not enter the financial market, then the illiquidity parameter is infinite so that $\zeta^{-1}$ is zero. The expected dividend when the individual investor is not present is $H-L$, whereas this quantity when the individual investor is present is $(1-p)(H-L)$. From the regulatory authority's objective function and Equation (7), we then have that $v_{\epsilon}^{S}$ is preferred if (9) holds, and

$$
(1-w)(H-L)>w\left(2 / v_{\delta}\right) \sqrt{\left(v_{\delta}+v_{\epsilon}^{S}\right) v_{z}}+(1-w)(1-p)(H-L)
$$

The above condition reduces to Condition (10) in the proposition.

Proof of Proposition 7: For part 1, note that the entry condition for the I'th investor is

$$
(2 I)^{-1} \operatorname{std}(\delta) \operatorname{std}(z)<K-C_{E}+\max \left[\beta I^{-1}\left(1-p^{I}\right)(H-L)-C_{I}, 0\right] .
$$

If $K-C_{E}>0$, then, as $I \rightarrow \infty$, the left-hand side of the above inequality goes to zero whereas the right-hand side remains positively bounded. Thus, so long as the maximum number of individual investors, $I_{m}$, is high enough, an equilibrium where all $I_{m}$ individual investors enter the market exists. The proof of Parts 2 and 3 of Proposition 7 is a simple modification of that of Proposition 2. 
Proof of Proposition 8: The mean of the prior distribution of $\gamma_{p}$ is $\gamma_{m}=\gamma_{1} /\left(\gamma_{1}+\gamma_{2}\right)$. From By the law of iterated expectations, the ex ante expected compensation of each firm becomes

$$
E_{a}=[q p+1-q] \gamma_{1} /\left(\gamma_{1}+\gamma_{2}\right)
$$

A standard result in statistics (e.g., DeGroot, 1989) implies that the posterior distribution of $\gamma_{p}$ will be a beta distribution with parameters $\gamma_{1}+m$ and $\gamma_{2}+n-m$. The ex ante expected compensation for each firm now becomes

$$
E_{a}^{\prime}=[q p+1-q]\left[\left(\gamma_{1}+m\right) /\left(\gamma_{1}+\gamma_{2}+n-m\right)\right]
$$

Comparing the right-hand sides of Eqs. (19) and (20), $E_{a}^{\prime}>E_{a}$ if and only if

$$
\gamma_{1} /\left(\gamma_{1}+\gamma_{2}\right)<\left[\left(\gamma_{1}+m\right) /\left(\gamma_{1}+\gamma_{2}+n-m\right)\right]
$$

which, upon algebraic simplification, reduces to the condition in the proposition. 
This table presents the summary statistics for the data used in the empirical tests. We use a sample of NYSE/AMEX stocks from the year 2001. Total compensation is salary plus bonus plus all other compensation including option grants, averaged across the top five executives for each firm. The other variables are total dollar volume, number of business segments, return volatility (standard deviation of daily returns) and skewness over the year, the compounded stock return over the past thirty-six months, and market capitalization as of the end of the year (firm size).

\begin{tabular}{lrlc}
\hline Variable & Mean & Median & Std. Dev. \\
\hline Total compensation (\$ millions) & 3.115 & 1.526 & 5.476 \\
Trading volume $\$$ billions) & 2.910 & 0.132 & 12.070 \\
Number of business segments & 2.169 & 1.000 & 1.619 \\
Return volatility & 0.044 & 0.026 & 0.332 \\
Return skewness & -0.073 & 0.023 & 2.393 \\
Return & 0.220 & 0.026 & 1.440 \\
Firm size (\$ billions) & 2.120 & 0.164 & 12.918 \\
\hline
\end{tabular}


Table 2: Cross-Sectional Regressions for Total Executive Compensation

This table presents the results of individual stock executive compensation using the logarithm of total compensation (salary plus bonus plus all other compensation including option grants) as the dependent variable. The explanatory variables are total dollar volume, return volatility (standard deviation of daily returns) and return skewness over the year, number of business segments, market capitalization as of the end of the year (firm size), and the compounded stock return over the past thirty-six months. The second and third columns report results averaged across the top five executives (ranked by the dependent variable) within each firm. The fourth and fifth columns report results averaged by firm across all executives whose compensation levels are reported in the Execucomp database. We use logarithms of all variables except return volatility, return skewness, and return. The data are for NYSE/AMEX stocks from the year 2001.

\begin{tabular}{l|rr|rr}
\hline & \multicolumn{2}{|c|}{ Top five executives } & \multicolumn{2}{c}{ All reported executives } \\
\hline Variable & Coeff. & \multicolumn{1}{c}{-stat. } & Coeff. & $t$-stat. \\
\hline Trading volume & 0.278 & 8.12 & 0.271 & 7.92 \\
Number of business segments & -0.039 & -1.15 & -0.041 & -1.21 \\
Return volatility & 5.81 & 3.95 & 5.78 & 3.86 \\
Return & -0.007 & -0.28 & 0.013 & 0.57 \\
Return skewness & -0.009 & -0.87 & -0.008 & -0.73 \\
Firm size & 0.158 & 3.78 & 0.157 & 3.72 \\
\hline Adjusted $R^{2}$ & 0.585 & & 0.563 & \\
\hline
\end{tabular}


Table 3: Cross-Sectional Regressions for Indirect Executive Compensation

This table presents the results of individual stock indirect executive compensation using the sum of long-term incentive payouts (payments emanating from incentives set by management), and all other compensation (excluding salary and bonus), as a proportion of total compensation as the dependent variable. The explanatory variables are total dollar volume, relative small order volume (proportion of dollar volume emanating from trades of less than 500 shares), return volatility (standard deviation of daily returns) and return skewness over the year, the compounded stock return over the past thirty-six months, the number of business segments, market capitalization as of the end of the year (firm size), and the proportion of stock held by institutions. The second and third columns report results averaged across the top five executives (ranked by the dependent variable) within each firm. The fourth and fifth columns report results averaged by firm across all executives whose compensation levels are reported in the Execucomp database. We use logarithms of all variables except return volatility, return skewness, and return (institutional holdings are logistically transformed). The data are for NYSE/AMEX stocks from the year 2001 .

\begin{tabular}{l|rr|rr|rr}
\hline & \multicolumn{4}{|c|}{ Top five executives } & \multicolumn{3}{c}{ All reported executives } \\
\hline Variable & Coeff. & t-stat. & Coeff. & $t$-stat. & Coeff. & $t$-stat. \\
\hline Total volume & 0.072 & 0.60 & 0.124 & 1.02 & 0.116 & 0.93 \\
Number of business segments & 0.177 & 1.65 & 0.098 & 0.91 & 0.230 & 2.05 \\
Return volatility & -1.54 & -0.18 & 13.02 & 1.25 & 16.13 & 1.50 \\
Return skewness & 0.008 & 0.26 & 0.028 & 0.88 & 0.016 & 0.47 \\
Return & 0.056 & 0.39 & -0.011 & -0.07 & 0.097 & 0.70 \\
Firm size & -0.104 & -0.73 & -0.034 & -0.23 & -0.061 & -0.39 \\
Relative small order volume & - & - & 0.367 & 2.33 & 0.348 & 2.13 \\
Institutional holdings & - & - & -0.108 & -2.42 & -0.119 & -2.61 \\
\hline Adjusted $R^{2}$ & 0.027 & & 0.081 & & 0.121 & \\
\hline
\end{tabular}

